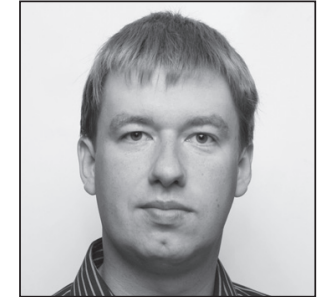

Kristjan Kask

PhD, Researcher

University of Tartu

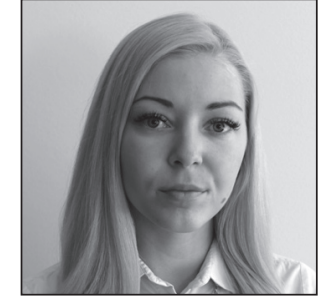

Sandra Salumäe

Master's student

University of Tartu

\title{
The Analysis of Complex Forensic Psychiatry and Psychology Expert Assessments in Estonia
}

\section{Introduction}

Every year, several hundred forensic psychiatry and psychology expert assessments are conducted on persons on whom an examination ruling has been issued by the body conducting proceedings (or 'BCP'). ${ }^{*}$ However, it is not known how frequent the cases are wherein the assessment identifies the presence of a 'mental and behavioural disorder'. Therefore, complex forensic psychiatric- and psychological-examination-based assessments in the years 2011 and 2012 are examined.

The composition of expert assessments is regulated by the Forensic Examination Act (FEA). ${ }^{{ }_{2}}$ Under the FEA's $\S 4$ (1), an expert is a person who uses non-legal special knowledge for conducting expert assessment in his or her field of expertise. An expert may also, under the FEA's $\$ 4$ (2), be either a forensic expert (who works at the relevant state institute of expertise and whose main task is to conduct expert assessments by dint of the FEA's $\S 4$ or a state-acknowledged expert (i.e., someone recognised as an expert by the state).

\subsection{Capability of guilt}

A person is capable of guilt when he or she is mentally capable and at least 14 years old, according to $\S 33$ of the Penal Code (PC) ${ }^{*}$. If a person is mentally capable, then he or she has understanding of the lawfulness of the act committed and is capable also of acting accordingly. If this ability is absent or limited, the person is not mentally capable (PC, §34) or has diminished mental capacity (PC, §35). Accordingly, a person is deemed mentally incapable (under the PC's §34) when he or she is incapable of understanding the unlawfulness of the act or incapable of acting according to such an understanding for reason of mental illness, temporary severe mental disorder, mental disability, feeble-mindedness, or any other severe mental disorder. A person can be considered as of diminished mental capacity (PC, §35) if there are statuses present that are consistent with the PC's §34, subsections 1-5 but at the same time the intensity thereof does not exclude his or her ability to understand the unlawfulness of his or her act or to act in accordance with such

\footnotetext{
Kuritegevus Eestis 2014 (Crime in Estonia 2014). Tallinn: Justiitsministeerium 2015.

2 Forensic Examination Act (Kohtuekspertiisiseadus). - RT I, 16.4.2014, 6 (in Estonian).

3 Penal Code (Karistusseadustik). - RT I, 23.12.2014, 16 (in Estonian).
} 
an understanding. Therefore, if there is a doubt on the part of the BCP with respect to the suspect or accused corresponding to one of the statuses specified in the PC's §34, subsections 1 to 5 , then an examination ruling is prepared wherein the circumstances of the crime, the reason for obtaining the expert assessment, and the area for assessment are stated, along with the questions to which the BCP wishes to have an answer.

Thus, fulfilling both medical and judicial criteria is important in establishing the capability of guilt.." ${ }^{*}$ The judicial criteria for mental incapability are understanding of the unlawfulness of the act and the ability to act accordingly, whereas the medical criteria describe the pathological states of the organism that influence the person's understanding of the unlawfulness of the act or guide his or her action. ${ }^{*}$ Judicial criteria are to be applied only on the basis of the medical criteria, whilst medical criteria should be evaluated in line with judicial features (the person should be able to understand the unlawfulness of his or her behaviour and have the ability to guide his or her acts). ${ }^{*}$ The person is incapable of guilt if both criteria are fulfilled; if the medical criteria are present but the person can understand the unlawfulness of the act and also guide his or her acts accordingly, that person cannot be judged incapable of guilt (but diminished capability of guilt may be present). ${ }^{*}$ Capability of guilt should be taken to refer to only the context of the precise act during commission of the crime. ${ }^{*} 8$

The medical features of mental incapability demonstrate the pathological phenomena in the organism that should be evaluated with respect to mental capacity during commission of the act. ${ }^{*} 9$ J. Sootak and P. Pikamäe have described these conditions in greater depth. A 'mental illness' is characterised by skewed perception of reality, difficulties in adaptation to reality, and change in the structure of the personality. A 'temporary severe mental disorder' is a severe mental disorder that lasts hours to weeks and is often generated by external factors such as loss of consciousness due to brain trauma or delirium arising from intoxication. 'Mental disability' refers to mental retardation that is long-lasting in the course of the individual's life and characterised by lower levels of perception, speech, motor skills, and communication. 'Feeble-mindedness' is a state wherein there is dysfunction in memory and thinking abilities that interferes with the person's everyday life and functioning. Finally, the category 'any other severe mental disorder' involves disorders that can have an effect on the understanding of the act and capability to guide one's acts at a level such that the person is not capable of understanding.

Sootak has noted that if an examination ruling has been issued, one or more experts establish the presence of the symptoms of the mental disorder along with the clinical picture, diagnose the disorder (if present), and evaluate whether the medical condition corresponds to the criteria of the PC (in §34 (1)-(5)). ${ }^{* 10}$ For example, the person may be diagnosed with an acute psychotic disorder (a disorder is a clinically recognisable constellation of symptoms or behaviour that is accompanied by distress and that interferes with the person's functioning ${ }^{*}{ }^{11}$ ) present during commission of the act that corresponds to the judicial criteria for a mental illness as the person was not able to guide his or her acts and to understand the unlawfulness of his or her behaviour. In court, the judge subsumes this by using PC's $\S 34$ since the person did not possess understanding of the unlawfulness of his or her act and therefore is incapable of guilt. ${ }^{*}$

\subsection{A highly provoked state}

Another element prevalent in $\mathrm{BCP}$ examination rulings involves issues related to an act committed by someone in a highly provoked state, which may be a circumstance mitigating guilt (as in the case of provoked murder according to the PC's §115, with an example being murder carried out under the influence of a sudden-onset

4 J. Sootak, P. Pikamäe. Karistusseadustiku kommenteeritud väljaanne 3. trükk (Commentaries to the Penal Code, 3rd edition). Juura 2009, pp. 175-178 (in Estonian).

5 Ibid., pp. 175-178.

Ibid., pp. 175-178.

Ibid., pp. 175-178.

8 A. Aadamsoo. Süüdimatuse meditsiinilised tunnused (Medical Features of Incapability of Guilt). - Juridica 2/2002, pp. 100-102 (in Estonian).

9 J. Sootak, P. Pikamäe (see Note 4), pp. 175-178.

10 J. Sootak. Süüvõime karistusseadustikus (Capability of Guilt in the Penal Code). - Juridica II/2002. pp. 85-86 (in Estonian).

11 World Health Organization. The ICD-10 Classification of Mental and Behavioural Disorders: Clinical descriptions and diagnostic guidelines, 1992. Available at http://www.who.int/classifications/icd/en/bluebook.pdf (most recently accessed on 15.3.2015), p. 11.

12 J. Sootak (see Note 10), pp. 85-86. 
highly provoked state). ${ }^{* 13}$ It had already been declared in the Law of Punishment, in 1903, that murder and causing severe harm to the health can be committed under the effect of 'great soul-based anxiety'. The basis for privilege here is not the type of intent but an emotional state wherein emotions interrupt the process of normal motivation. ${ }^{*} 14$ Because many of the expert assessments are made in cases of crimes of first or second degree, evaluation of the presence of a highly provoked state is an important issue to address.

There has been discussion in the literature of differences in interpretation of the term 'highly provoked state' between lawyers and the experts. ${ }^{.} 15$ Often, the BCP asks experts to identify a 'highly provoked state' or 'affect'; however, these terms are not synonyms. The former is a juridical term, whereas the latter is based more on behavioural science. Bridging the gap, the wording 'a physiological affect' is used. Judicially certain conclusions can be made on the basis of this, but, since this state does not belong to any of the specified medical conditions, it is difficult for the experts to identify such a state: there is no disorder using the name 'affect' in the ICD-10. ${ }^{* 16}$ The closest cluster to a condition of this nature is the neurotic disorders, in which all the features are present that are encompassed by physiological affect. In practice, the following procedure is applied. During the complex expert assessment, the state of the person's health is given a diagnostic evaluation (for example, as a neurotic disorder) and also an evaluation addressing the expression of the state - i.e., whether the person is capable of understanding the circumstances and guiding his or her actions accordingly. ${ }^{*}{ }^{17}$ Then the evaluation is rendered in terms of physiological affect. Therefore, if the person's capacity of understanding is diminished, then that person has been in a state characterised by the physiological affect and if not, there are no signs of the relevant physiological affect. ${ }^{*} 18$

However, in a highly provoked state, one may present very intense emotions that do not require an assumption of pathology. Accordingly, this condition is not diagnosable in terms of ICD-10 criteria and lies within the competence of forensic psychological but not psychiatric expert assessments. Therefore, the aim is not to establish the presence of a mental disorder but rather to identify a specific state. In sum, as the human mental state is often complicated and these conditions difficult to delimit, the most rational approach is to use complex expert assessment. ${ }^{* 19}$

\subsection{The study}

The aim with this paper is to analyse complex expert assessments in forensic psychiatry and psychology. Firstly, the prevalence of mental disorders in expert assessment acts is examined (i.e., how often there are cases that correspond to the statuses in the PC's §34, subsections 1 to 5). Secondly, the wording of questions asked of the experts by the BCP in the examination rulings is analysed, with special attention directed to whether the questions posed can be legitimately answered by the experts or instead exceed their field of expertise. Access to the examination rulings and assessment reports was granted by the Estonian Forensic Science Institute, and permission to analyse sensitive personal information was obtained from the Estonian Data Protection Inspectorate.

\section{Results}

In total, access to 76 expert assessments from 2011 and 2012 was gained. Fifty-five expert assessments of suspects were included for the present analysis; the cases of minors under the age of 14 and of victims were excluded, as these did not focus on issues related to capability of guilt.

13 T. Kompus. Emotsionaalsete seisundite hindamine kohtupsühholoogilisel ekspertiisil (Evaluating Emotional Statuses in Forensic-psychology Expert Assessment).. - Juridica II/2002, pp. $96-99$ (in Estonian).

14 J. Saar, P. Pikamäe. Hingelise erutuse seisund. Probleemidest Eesti karistusõiguses ja kohtupraktikas (Highly Provoked State: Problems in Estonian Penal Law and Practice). - Juridica IX/2006, pp. 591-600 (in Estonian), p. 592.

15 T. Kompus (see Note 13); J. Saar, P. Pikamäe (see Note 14); P. Randma. Afekt kui hingelise erutuse seisund ja ajutine raske psüühikahäire (Affect as Highly Provoked State and Temporary Severe Mental Disorder). - Juridica V/2005, pp. 321-331 (in Estonian).

16 World Health Organization (see Note 11).

$17 \quad$ P. Randma (see Note 15). p. 324.

18 T. Kompus (see Note 13), pp. 97-99.

19 J. Saar, P. Pikamäe (see Note 14), pp. 597-598. 
The assessments were conducted by 18 experts; for one expert assessment act, the experts were not listed. As only complex assessments were analysed, usually the evaluations were conducted by a psychiatrist and a psychologist, but there were situations wherein the assessment was made by two psychiatrists (in cases of in-patient care). Of the 18 experts, three were state-acknowledged experts (two medical doctors in psychiatry and one clinical forensic psychologist), four experts were psychologists, and 11 were medical doctors in psychiatry. Three doctors conducted more than 10 assessments each (range: 10-14, accounting for $67.3 \%$ of the assessments in all), and eight doctors performed fewer than 10 (range: 1-6). The selection of psychologists was narrower; only four persons were used (one of them a state-acknowledged expert). One psychologist had performed 28 assessments (50.9\%), another had completed 19 (34.5\%), and the remaining two made one expert assessment each.

The mean age of the persons assessed was 33 years (with a range of 14 to 65 years), and they included 45 men and 10 women. By nationality, 20 persons were Estonians, 31 were Russians, and one was of another nationality; there were no data for two persons. The mean delay between commission and assessment was six months. There were situations wherein the assessment took place less than a month from the commission, while the longest delay was 52 months. Also registered was the cost of the experts' assessments ${ }^{* 20}$. The cost varied from 255 to 2,350 euros, with the mean cost being 912 euros. The average cost of those expert assessments that suggested the person to correspond to the criteria of PC §34’s subsections 1 to 5 did not differ statistically significantly from that of the assessments in which the person were deemed not to correspond to the criteria.

\subsection{Preliminary psychiatric history and previous expert assessments}

As judged by recorded previous psychiatric history, 26 persons (47.3\%) had no psychiatric history, while the others had visited specialists (psychiatrists, psychologists, or both) one to seven times, on average once or twice. Of those who were assigned for evaluation, four persons were suggested later to be mentally incapable. With respect to history of psychiatric treatment in hospital, similarly, for 26 persons (47.3\%) there was no history present. Others had been in hospital once, on average, and one person (suggested as mentally incapable) had been hospitalised 19 times. Previous expert assessments had not been conducted for 42 persons (76.4\%; seven of them suggested as mentally incapable), 11 individuals had been subject to expert assessments once (with two of them suggested to be mentally incapable), and two persons had been evaluated twice before. The qualifications for which expert assessments were sought most often by the BCP were manslaughter and threat (see Table 1). Most often, one qualification associated with penal power was involved (41 cases, $74.5 \%$ ); in 13 cases there were two and in one case three qualifications present.

Table 1: Frequency of qualifications in line with which the suspects were accused

\begin{tabular}{|c|c|}
\hline Qualification according to the Penal Code & Instances \\
\hline$\S 113$, manslaughter & 13 \\
\hline$\S 114$, murder & 5 \\
\hline$\S 118$, causing serious harm to health & 6 \\
\hline$\S 120$, threat & 7 \\
\hline$\S 121$, physical abuse & 12 \\
\hline$\S 141$, rape & 2 \\
\hline$\S 199$, larceny & 3 \\
\hline$\S 200$, robbery & 2 \\
\hline$\S 203$, damage or destruction of a thing & 1 \\
\hline$\S 213$, computer-related fraud & 1 \\
\hline$\S 214$, extortion & 1 \\
\hline$\S 215$, unauthorised use of a thing & 1 \\
\hline$\S 263$, aggravated breach of public order & 4 \\
\hline
\end{tabular}

20 Formulated in Forensic Examination Act $§ 27^{5}$ 's subsections 1 to 5 . 


\begin{tabular}{|l|c|}
\hline $\begin{array}{l}\text { §274, violence against a representative of state authority or another } \\
\text { person protecting public order }\end{array}$ & 4 \\
\hline$\S 331^{2}$, violation of a restraining order & 1 \\
\hline $\begin{array}{l}\text { §422, violation of traffic requirements or vehicle operation rules } \\
\text { by a driver }\end{array}$ & 1 \\
\hline $\begin{array}{l}\text { §424, driving a motor vehicle, off-road vehicle, or tram in a state } \\
\text { of intoxication }\end{array}$ & 1 \\
\hline $\begin{array}{l}\text { §275, defamation or insulting of a representative of state authority } \\
\text { or another person protecting public order }\end{array}$ & 1 \\
\hline $\begin{array}{l}\text { §303, violence against judges, lay judges, preliminary investigators, } \\
\text { prosecutors, criminal defence counsel, representatives of victims, } \\
\text { or persons close to them }\end{array}$ & 1 \\
\hline §404, arson & \\
\hline
\end{tabular}

\subsection{The appearance of statuses provided for by PC' $\S 34$ (1)-(5)}

In nine cases (16\%), there were conditions suggesting a conclusion of mental incapability according to Penal Code $\S 34$ 's subsections 1 to 5 ( $16.4 \%$ of the cases, all of men $)^{* 21}$; in the court hearing stage, this number increased to 10 (since one person was diagnosed with an acute schizophrenia-like psychotic disorder). As for qualifications, in three cases the suspect was accused in line with the PC's $\S 120$ (see Table 1); in one case, PC §118, §141, §199, or §422 was the relevant section; and in two cases the accusations were in accordance with two PC qualifications, either $\S 120$ and $\S 121$ or $\S 121$ and $\S 263$. It should be acknowledged that the presence of the statuses is judged from the conclusion of the expert assessment acts and not by the court verdicts. Next, the appearance of the statuses specified in the PC's \$34 (1)-(5) is introduced, by disorder cluster. The general characteristics of these disorders are described in terms of ICD-10 diagnostic criteria firstly, after which their correspondence to PC 334 (1)-(5) is discussed.

\subsubsection{Organic mental disorders}

Organic mental disorders are characterised by a common demonstrable aetiology in cerebral disease, brain injury, or other insult leading to cerebral dysfunction. ${ }^{* 22}$ The dysfunction may be primary, as in cases of diseases, injuries, and insults that affect the brain directly and selectively, or secondary, as in systemic diseases and disorders that attack the brain only as one of the multiple organs or systems of the body that are involved. ${ }^{* 23}$ In our analysis, there were four persons (7.4\%) diagnosed with disorders in this cluster (the diagnoses were organic personality disorder, organic hallucinosis, and post-traumatic brain damage syndrome); two of the four persons assessed were suggested to be mentally incapable as they corresponded to the characteristics outlined in the PC's $\S 34$ (1)-(5).

\subsubsection{Mental and behavioural disorders due to use of psychoactive substances}

The disorders due to use of psychoactive substances differ in severity and clinical form but are all attributable to the use of one or more of these substances, which may or may not have been medically prescribed. ${ }^{* 24}$ For example, acute intoxication is a condition that follows the administration of a psychoactive substance and results in disturbances in level of consciousness, cognition, perception, affect or behaviour, or other psycho-physiological functions and responses. ${ }^{* 25}$ The disturbances are directly related to the acute

21 It has to be noted that the court verdicts in these cases are not known so these decisions are based solely on the expertassessment acts.

22 World Health Organization (see Note 11), p. 45.

23 Ibid., p. 45.

24 Ibid., p. 67.

25 Ibid., p. 67. 
pharmacological effects of the substance and resolve with time, with complete recovery except where tissue damage or other complications are present. ${ }^{*_{2} 6} \mathrm{~A}$ dependence syndrome is defined as behavioural, cognitive, and physiological phenomena that develop after repeated substance use and that typically include a strong desire to take the drug, difficulties in controlling its use, persistence in its use without regard for harmful consequences, a higher priority given to drug use than to other activities and obligations, increased tolerance, and sometimes a physical withdrawal state. ${ }^{*}{ }^{27}$ Firstly, the conditions related to alcohol were analysed, followed by the use of other substances. Nineteen persons were intoxicated by alcohol during commission of the act (34.5\%), and none of them met the criteria in PC's $\S 34$ (1)-(5). Dependence on alcohol was established in 14 cases (25.5\%), with three of the individuals suggested to be mentally incapable. In the use of other psychotropic substances, the use of tranquillisers, caffeine, and heroin was noted (which occurred also concomitantly with use of alcohol) to be prevalent for five persons (9\%), who were all concluded to be mentally capable.

\subsubsection{Schizophrenia and schizotypal and delusional disorders}

The schizophrenic disorders are characterised by fundamental and characteristic distortions of thinking and perception, along with emotions that are inappropriate or blunted. ${ }^{* 28}$ Clear consciousness and intellectual capacity are usually maintained, although certain cognitive deficits may evolve in the course of time. ${ }^{* 29}$ The most important psychopathological phenomena include thought echo; thought insertion or withdrawal; thought broadcasting; delusional perception and delusions of control, influence, or passivity; hallucinated voices commenting or discussing the patient in the third person; thought disorders; and initial negative symptoms. ${ }^{*} 30$ In our analysis, it was mostly a diagnosis of paranoid schizophrenia that was present; an acute schizophrenia-like psychotic disorder (with symptoms similar to those of schizophrenia but persisting less than one month) was noted too. Eight persons (14.5\%) were diagnosed with these disorders, seven of whom corresponded to the criteria of PC' $\$ 34(1)-(5)$ and were therefore suggested as being mentally incapable.

\subsubsection{Personality disorders}

The personality disorders cover a variety of conditions and behaviour patterns of clinical significance that tend to be persistent and appear to be the expression of the individual's characteristic lifestyle and mode of relating to himself or herself and others. ${ }^{* 31}$ Some of these conditions and patterns of behaviour emerge early in the course of the individual's development, as a result of both constitutional factors and social experience, while others are acquired later in life. ${ }^{*} 32$ They represent extreme or significant deviations from the way in which the average individual in a given culture perceives, thinks, feels, and (in particular) relates to others. ${ }^{*} 33$ Such behaviour patterns tend to be stable and to encompass multiple domains of behaviour and psychological functioning. ${ }^{*} 4$ They are frequently, but not always, associated with various degrees of subjective distress and problems of social performance. ${ }^{*} 35$ These are severe disturbances in the personality and behavioural tendencies of the individual not directly resulting from disease, damage, or other insult to the brain or from another mental disorder. The disturbances usually involve several aspects of personality, nearly always are associated with considerable personal distress and social disruption, and generally have manifested themselves since childhood or adolescence before continuing throughout adulthood. ${ }^{*}{ }^{6}$ Personality disorders were diagnosed in 16 cases (29.1\%). Most were of the antisocial and emotionally unstable

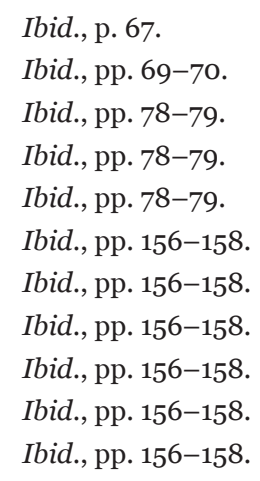


personality disorder with explosive manifestations, but there were also mixed-type personality disorders. All persons diagnosed with personality disorders were concluded to be mentally capable.

\subsubsection{Mental retardation}

Mental retardation is a condition of arrested or incomplete development of the mind and is characterised especially by impairment of skills manifested during development, skills that contribute to one's overall level of intelligence - i.e., cognitive, language, motor, and social abilities. ${ }^{*} 7$ Mental retardation can occur with or without any other mental or physical condition. Mental retardation was diagnosed in three cases (5.5\%), and the persons in question were all suggested to be mentally capable. The relevant persons were diagnosed as having mild mental retardation (likely to result in some learning difficulties in school, while many adults with this diagnosis are able to work and maintain good social relationships and contribute to society) sometimes alongside behavioural disorders and, in one case, antisocial personality disorder.

\subsection{Categories of questions asked for the expert assessments}

In total, 62 questions, with varying wording, were asked of the experts in examination rulings by the BCP. The questions were grouped into small categories on the basis of the topic the BCP dealt with in the examination rulings; see Table 2. As the table shows, mostly the questions addressed the compatibility of the person's status with the PC's $\S 34$ (1)-(5); in a lesser extent, the BCP wished to clarify issues pertaining to the necessity of coercive treatment, ability to testify in court and serve the sentence, and the presence of mental disorders (with questions posed both in medical and in judicial terms). Seventy-six per cent $(n=276)$ of the questions were answered separately (i.e., one question and one answer), and $24 \%(n=85)$ were answered together (one answer for at least two questions - i.e., the experts answered several questions, of similar content, together). Different phrasing of the questions was used with respect to issues of compatibility with PC $\$ 34$ and the presence of a mental disorder in medical terms. Of the questions addressing the presence of mental disorders with a time dimension, $48 \%(n=43)$ of the questions asked dealt with the present (i.e., the time of the trial in court), $48 \%(n=43)$ addressed the past (i.e., the time of commission of the act), and $4 \%(n=4)$ had to do with the dynamics of the condition between those two points. Next, the most common categories of questions asked of the experts are examined more closely.

Table 2: Percentages of questions asked of the experts by a body conducting proceedings in its examination rulings, by category

\begin{tabular}{|l|c|c|c|}
\hline & Percentage & $\begin{array}{c}\text { Number } \\
\text { of questions } \\
\text { using the term }\end{array}$ & $\begin{array}{c}\text { Number } \\
\text { of wordings } \\
\text { of the questions }\end{array}$ \\
\hline $\begin{array}{l}\text { Suffering or having suffered a mental disorder } \\
\text { (judicial term) }\end{array}$ & 13 & 46 & 2 \\
\hline Highly provoked state & 4 & 16 & 7 \\
\hline Necessity of a lawyer's presence & 2 & 7 & 2 \\
\hline Necessity of coercive treatment & 18 & 65 & 4 \\
\hline Compatibility with PC §34 & 28 & 100 & 17 \\
\hline Capacity to testify in court / serve the sentence & 14 & 52 & 11 \\
\hline Presence of a mental disorder (medical term) & 12 & 44 & 3 \\
\hline Presence of physiological affect & 4 & 14 & 4 \\
\hline Veracity of the statements & 2 & 6 & 2 \\
\hline The influence of medication on the person & 0.5 & 2 & 5 \\
\hline Cognitive function disorders & 1.5 & 5 & 2 \\
\hline Inclination toward criminal behaviour & 0.5 & 2 & 2 \\
\hline Dynamics of mental health status & 0.5 & 2 & \\
\hline
\end{tabular}

37 Ibid., pp. 176-177. 


\subsubsection{Suffering or having suffered a mental disorder (in judicial or medical terms)}

Questions in the first category were asked both in medical terms (i.e., with regard to a mental disorder) and in judicial terms (with a literal translation to 'malfunction of the action of the mind') with reference to the statuses listed in PC' $\$ 34$ (1)-(5). The experts answered these questions mainly by indicating the diagnosis (or diagnoses) of the person and the effect of the indicated disorders on understanding of the lawfulness of the act or capability of acting in line with such an understanding. The questions were worded for investigation of both situations, present and past (where these two contexts refer to the act's commission and the trial).

\subsubsection{Highly provoked state and/or the presence of a physiological affect}

The experts in their answers stated that the terms 'highly provoked state' and 'physiological affect' are not precise in content or do not correspond to the emotional statuses in current psychological literature and that, therefore, establishing these states in an expert opinion is not possible. In some wordings of the questions, the term 'neurotic disorder' was present; also, there were questions addressing whether the state (also worded as 'traumatic experience' or 'special emotional state') in question was present and how it affected understanding of the lawfulness of the act or influenced capability of acting accordingly, along with issues related to the duration of the highly provoked state. In some expert assessments, it was written that, although, because of incompatibility in terminology, it was not possible for the experts to identify the presence of a highly provoked state (e.g., this was not in their competence), no such behaviour occurred as the term entails. However, there were experts who answered the questions - i.e., who stated that there was no 'physiological affect' present. In sum, there is disagreement in the opinions of the experts themselves with respect to answering these questions, which indicates that this issue needs to be clarified, so as to prevent misunderstandings.

\subsubsection{Necessity of coercive treatment and capacity to testify in court / serve the sentence}

The necessity of coercive treatment is assessed largely via the criteria of the PC's $\S 86$. The experts stated that their opinions were based on the severity of the medical condition(s) of the examinees, considering also the facts of whether the person was of danger to him- or herself or to others. The associated question was asked also for better understanding of whether the person has a mental disorder and how the disorder, if any, affects his or her ability to give testimony in court. For example, experts found that a neurotic disorder does not limit a person's understanding of the surroundings or, in other cases, that the accused would need to be talked to in a simple manner but is able to be present in court. Issues related to serving the sentence were linked more to the issues of coercive treatment - the expert had to answer questions as to whether at present the person is capable of serving the sentence. There was a case wherein an acute psychotic disorder had been diagnosed in the accused by the trial date and the experts therefore answered that the accused was currently not able to understand the surroundings and, accordingly, not able to serve the sentence (although at the time of the act's commission the accused was capable of understanding the surroundings).

\subsubsection{Compatibility with PC $\S 34$}

The BCP asked experts often about the presence of mental disorders that could prove that a person was not able to guide his or her acts or understand the unlawfulness thereof in line with the specifications in the above-mentioned subsections of the PC's $\S 34$. However, someone may have a mental disorder that corresponds to the judicial criteria of statuses specified in the PC's $\$ 34$ while at the same time the expert may state that this did not affect the person's understanding or act as the intensity of the condition was low. Therefore, answering this question solely from the correspondence to the judicial or medical criteria might not be correct. For example, five times the question was asked in such a manner that the expert was to present an answer as to guilt capacity (which Sootak ${ }^{*} 38$ argues is the decision of the judge). In summary, there

${ }_{38}$ J. Sootak (see Note 10), p. 86. 
were cases in which the question was answered by the experts but also cases wherein the experts stated that answering this question was not within their competency.

\subsubsection{Veracity of the statements}

The experts were asked to state a conclusion (working also from the history of the examinee) as to whether someone could have influenced the individual's testimony or whether that person's testimony is credible. In these cases, the experts answered that there were no mental disorders that affected the person's memories or abilities to present those memories both orally and in writing. However, it was stated also that the term 'credibility of the statements' does not lie within the competency of the experts and therefore the question posed in that connection cannot be answered.

\section{Conclusions}

This paper has analysed the prevalence of mental disorders in forensic psychiatry and psychology expert assessment acts of a complex nature and the questions the BCP has asked of the experts in the examination rulings in the years 2011 and 2012. The following conclusions are drawn on the basis of that analysis.

If the BCP has doubts about the suspect's or accused's capability of guilt, then an expert assessment is necessary, as the designated experts possess specific knowledge that can be used to verify whether the person is or was capable of understanding the situation and able to guide his or her actions both during the commission of the act and in court, which information helps the court to formulate a just decision. It needs to be debated whether the complex expert assessment as it stands is the best method for assessing the accused, but involving expert knowledge is clearly necessary.

Assessing mental disorders is difficult without special knowledge of this field. For example, being intoxicated by psychotropic substances can produce symptoms similar to those of a more serious mental disorder. The questions asked by the BCP about the past and the present have their place in clarifying the person's mental state - as it is dynamic rather than static, changes in state clearly can take place between commission and the trial in court. However, since this paper has examined decisions solely on the basis of expert assessments regarding capability of guilt, not from court verdicts, generalisation of these findings should be performed with care.

The BCP should be more precise in wording the questions in examination rulings, especially those addressing issues dealt with in the PC's $\$ 34$ (1)-(5). In cases of doubt that may nonetheless remain, the question(s) should be formulated such that if the substance is not within the competence of the experts they are to say so. The data indicated that the experts can provide answers to most categories of questions employed. There tended to be some categories of questions - such as those about inclination to criminal behaviour or veracity of statements - that produced mostly responses that these issues lie outside the competency of the experts, whereas the questions as to the compatibility of the person's status with the PC's $\S 34$ (1)-(5) were answered (i.e., those with judicial terms translated into medical terms and vice versa). However, when the BCP formulated the question in such a manner that the experts had to provide a direct answer regarding whether the person was mentally capable, incapable, or of diminished capability (in line with the PC $\$ 34$ or §35), discrepancies between the experts’ responses emerged: in some cases, the experts formulated a categorical decision on that question (e.g., whether the individual was capable or incapable of guilt) whilst in other cases the experts noted that stating a conclusion on this would be beyond their expertise.

Thus, there is lack of a unified view in some domains in conducting of forensic psychiatry and psychology expert assessments. Direct guidelines would be needed on how the questions should be formulated in the examination rulings. 